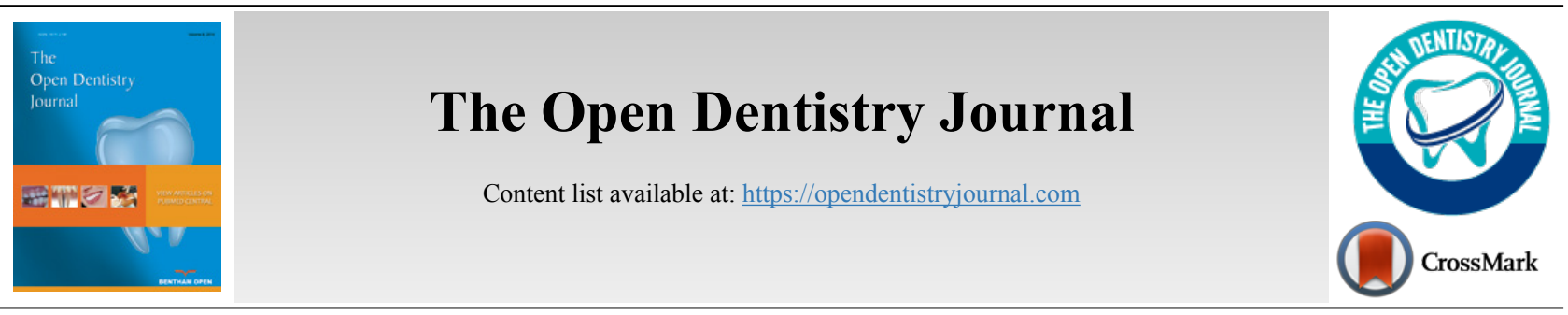

RESEARCH ARTICLE

\title{
Insights on Using Social Media in Dental Education: A Cross-Sectional Study in Saudi Arabia
}

\author{
Mona T. Rajeh ${ }^{1, *}$, Khalid T. Aboalshamat ${ }^{1}$, Afnan A. Nassar ${ }^{1}$, Shahinaz N. Sembawa ${ }^{1}$, Seba A. Al Hebshi ${ }^{2}$ and \\ Mohammad K. Badri ${ }^{3}$ \\ ${ }^{1}$ Department of Dental Public Health and Community Dentistry, College of Dentistry, Umm Al-Qura University, Makkah, Saudi Arabia \\ ${ }^{2}$ Faculty of Dentistry, King Abdul-Aziz University, Jeddah, Saudi Arabia \\ ${ }^{3}$ Department of Pedodontics \& Orthodontics, College of Dentistry, Taibah University, Madinah, Saudi Arabia
}

\begin{abstract}
:
Objective:

The purpose of this study is to investigate the insight of utilizing social media as an educational tool among dental faculty members in Saudi Arabia.

Methods:

A descriptive cross-sectional survey was distributed to 380 randomly selected faculty members from three governmental universities in the Western region of Saudi Arabia. The participants completed a validated questionnaire to assess the intent of using social media and their opinion about the benefits and drawbacks of adopting social media as an educational tool. Descriptive statistics and chi-square test were used to analyse the results.

Results:

Out of 380 faculty members who were invited to participate, 271 responded ( $71 \%$ response rate). Results reveal that WhatsApp, followed by YouTube, Facebook, and Twitter were the mostly used social media platforms. Around $31 \%$ of the participants reported using social media for ten hours or more. The main reason reported by the participants for using social media was searching for information (82.17\%), followed by professional networking $(78.29 \%)$ and learning $(75.97 \%)$. The majority of the participants agreed that social media have advantages like it helps students to communicate and share ideas with instructors, update students with new resources, and improve students' skills. Social media also has several disadvantages; the respondents believe that it can increase their addictive potential, create more demand for internet access, and raise concerns on direct contact with students.

\section{Conclusion:}

As an educational tool, social media can enrich the teaching experience by using the appropriate strategies. The findings may be useful for educators to adopt social media platforms in dental education.
\end{abstract}

Keywords: Dentistry, Education, Faculty members, Learning, Saudi arabia, Social media.

\begin{tabular}{|l|l|l|l}
\hline Article History & Received: October 10, 2020 & Revised: December 08, 2020 & Accepted: December 16, 2020
\end{tabular}

\section{INTRODUCTION}

Social media is an internet-based interactive technology that helps to create and share information [1]. Although social media platforms and apps were initially conceived as a means of socializing, they have gradually been adapted for education

\footnotetext{
Address correspondence to this author at Department of Dental Public Health, and Community Dentistry, Faculty of Dentistry, Umm Al-Qura University, Makkah, Saudi Arabia; E-mail: mtrajeh@uqu.edu.sa
}

-al purposes [2]. In recent studies, integrating social media tools into traditional education has increased collaborative student learning [3]. Researchers believe that interactive learning and greater collaboration among students lead to deeper learning levels [4 - 7].

Social media is growing in popularity among dentists and faculty members. Our initial literature search revealed that dental faculties and students frequently use social media [8]. According to a survey in the United States, $50 \%$ of dentists 
reported using it, with Facebook being the most frequently used (97\%), followed by LinkedIn (38\%) and then Twitter (32\%) [9]. However, dentists in South Africa mainly reported using Google+ and Facebook [10]. In a recent study that examined the use of social media among dentists in Riyadh, the capital of Saudi Arabia, half of the participants reported using social media in their practice for educational purposes and Twitter was the most widely used platform [11].

The emergence of social media has forced faculty members to think differently to enhance the learning process and incorporate social media into their teaching. Instructors from the University of British Columbia created a Facebook-like webpage for an operative dental course to facilitate interactive, cooperative learning and promote critical thinking [12]. A more recent study evaluated the effectiveness of using Facebook as an educational medium during a course involving a series of medical emergencies in dental practice. They concluded that Facebook provided a unique teaching environment that helped their students freely discuss topics in a flexible environment, regardless of time and place [13].

With the rapid growth of technology and the popularity of social media, the internet now has unprecedented potential to support learning. In the current situation of the COVID-19 pandemic, education has changed dramatically with the sudden increase in e-learning, where teaching is being carried out on digital platforms. Therefore, adopting social media in academia can facilitate creating a virtual community that can enhance learning. Although some studies have explored dental students' and faculties' usage of social media, none have focused on implementing social media in dental education. To address this knowledge gap, the present study aimed to identify perceptions pertaining to the use of social media tools in the learning context in Saudi Arabia.

\section{MATERIALS AND METHODS}

\subsection{Study Design and Study Population}

This was a descriptive cross-sectional study conducted among Saudi dental faculty members working in the three largest governmental dental schools in the Western province of Saudi Arabia (Umm Al-Qura University, King Abdul-Aziz University, and Taibah University). The study was conducted between November 2019 and May 2020 after obtaining ethical approval from the Faculty of Dentistry Institutional Review Board, Umm Al-Qura University, Makkah, Saudi Arabia (IRB number 155-2019). We calculated the sample size using an estimated prevalence of $50 \%$, a precision level of $5 \%$ and a confidence interval of $90 \%$. The minimum sample size required was 271 . We increased the sample size to 380 for an expected $40 \%$ dropout.

\subsection{Data Collection}

A self-administered questionnaire was distributed to randomly selected faculty members during workdays, at their free time, and it was collected immediately on completion. It took approximately five minutes to complete the questionnaire. The participants provided written informed consent, and their participation was voluntary and anonymous. No identifiable information was required to ensure the participants' confidentiality.

\subsection{Survey Instrument}

We used a self-administered validated questionnaire in English, adapted from a previous article [14]. To confirm the applicability and reliability of the questionnaire with Saudi dental faculties, we performed a pilot study with 15 dental faculty members of Umm Al-Qura University. After the pilot study, we modified and revised the questionnaire according to the participants' responses.

The final questionnaire comprised of four sections. The first section consisted of sociodemographic information like gender, age, years of teaching experience, and academic rank. The second section contained more specific questions on types of social media the participants use, average hours spent on social media, the reason for using social media, and if they use social media in the courses they teach. The third section addressed participants' perspectives on the benefits of social media use in education. While the last section contained questions on their views regarding the disadvantages of using social media in learning. Most questions were categorical response options. The last two parts were answered on five Likert-scale response options (ranging from 1= Strongly Disagree to $5=$ Strongly Agree) .

\subsection{Statistical Analysis}

Descriptive statistics was used to describe the participants' demographics, their social media usage, and their opinions on the benefits and disadvantages of using social media in dental education. Categorical data were studied using Chi-square and Fisher's exact test. Statistical analysis was performed using the Statistical Package for the Social Sciences (Version 16, SPSS Inc., Chicago, IL, USA). A value of $\mathrm{P}<0.05$ was considered statistically significant.

\section{RESULTS}

\subsection{Demographics}

We distributed the questionnaire to 380 randomly selected faculty members, of which, 271 completed the questionnaire (response rate 71\%). However, 13 surveys were excluded for incomplete data. The mean age of the respondents was $47.5 \pm$ 8.24. The demographic characteristics are given in Table $\mathbf{1}$.

Table 1. Participants' demographic variables.

\begin{tabular}{|c|c|c|c|}
\hline \multicolumn{2}{|c|}{ Demographic Characteristics } & N & \% \\
\hline College & King Abdul-Aziz University & 154 & 59.7 \\
\hline & Taiba University & 51 & 19.8 \\
\hline & Umm Al-Qura University & 53 & 20.5 \\
\hline
\end{tabular}




\begin{tabular}{|c|c|c|c|}
\hline Gender & Male & 134 & 51.9 \\
\hline & Female & 124 & 48.1 \\
\hline \multirow[t]{4}{*}{ Teaching experience } & Less than 5 years & 48 & 18.6 \\
\hline & 5 - 10 years & 76 & 29.5 \\
\hline & $11-15$ years & 39 & 15.1 \\
\hline & More than 5 years & 95 & 36.8 \\
\hline \multirow[t]{5}{*}{ Academic rank } & Demonstrator & 14 & 5.4 \\
\hline & Lecturer & 19 & 7.4 \\
\hline & Assistant professor & 91 & 35.3 \\
\hline & Associate professor & 82 & 31.8 \\
\hline & Full professor & 52 & 20.2 \\
\hline
\end{tabular}

\subsection{Background of Social Media Usage}

The questionnaire included questions related to the faculties' background of using social media (Table 2). The responses indicated that the majority of dental faculty members used internet for five to ten hours (38.4\%). The mean of social media accounts the respondents had is $(\mathrm{m}=7.03, \mathrm{sd}=2)$ accounts. Regarding the average number of hours, $31 \%$ of faculty members spent ten hours or more using social media per week. Amongst the studied population, social media tool mostly used was WhatsApp, followed by YouTube, Facebook, and Twitter. Using chi-square and fisher's exact tests, no significant association was found between gender and the different social media tools. However, we found that demonstrators, lecturers, and assistant professors were more likely to use Twitter, Instagram, and Snapchat compared to associate and full professors (Table $\mathbf{3}$ ).

Table 2. Social media account usage among dental faculty members.

\begin{tabular}{|c|c|c|c|}
\hline & & $\mathbf{N}$ & $\mathbf{\%}$ \\
\hline Item & Less than 5 & 38 & 14.7 \\
\hline Hours spent on the internet per week & 5 to less than 10 & 99 & 38.4 \\
\hline & 10 to less than 15 & 67 & 26.0 \\
\hline Hours spent on social media per week & 15 hours or more & 54 & 20.9 \\
\hline & Less than 3 & 34 & 13.2 \\
\hline & From 3 to less than 6 & 67 & 26.0 \\
\hline & From 6 to less than 10 & 77 & 29.8 \\
\hline Years since using social media & 10 hours or more & 80 & 31.0 \\
\hline & 0 to 3 years & 3 & 1.2 \\
\hline & More than 3 years & 255 & 98.8 \\
\hline & Not confident & 10 & 3.88 \\
\hline & Somewhat confident & 56 & 21.71 \\
\hline Cenerally, how confident do you feel about your skills in using Social Media? & Confident & 96 & 37.21 \\
\hline & Very confident & 96 & 37.21 \\
\hline & Arabic & 9 & 3.49 \\
\hline & English & 41 & 15.89 \\
\hline & Both & 208 & 80.62 \\
\hline
\end{tabular}

Table 3. Usage of social media accounts among dental faculty members.

\begin{tabular}{|c|c|c|c|c|}
\hline & $\begin{array}{c}\text { Total } \\
\mathbf{N}(\%)\end{array}$ & $\begin{array}{c}\text { Demonstrator/ lecturer } \\
\mathbf{N}(\%)\end{array}$ & $\begin{array}{c}\text { Assistant professor } \\
\mathbf{N}(\mathbf{\%})\end{array}$ & $\begin{array}{c}\text { Associate/ full professor } \\
\text { N (\%) }\end{array}$ \\
\hline WhatsApp & $253(98.06)$ & $33(100)$ & $87(95.6)$ & $133(99.25)$ \\
\hline YouTube & $190(73.64)$ & $24(72.73)$ & $63(69.23)$ & $103(76.87)$ \\
\hline Facebook & $178(68.99)$ & $20(60.61)$ & $61(67.03)$ & $97(72.39)$ \\
\hline Twitter & $156(60.47)$ & $24(72.73)$ & $71(78.02)$ & $61(45.52)^{*}$ \\
\hline Instagram & $146(56.59)$ & $26(78.79)$ & $64(70.33)$ & $56(41.79)^{*}$ \\
\hline Snapchat & $99(38.37)$ & $17(51.52)$ & $52(57.14)$ & $30(22.39)^{*}$ \\
\hline Other & $18(6.98)$ & $1(3.03)$ & $7(7.69)$ & $10(7.46)$ \\
\hline WordPress & $11(4.26)$ & $1(3.03)$ & $3(3.3)$ & $7(5.22)$ \\
\hline
\end{tabular}


Table 4. Reasons for using social media of dental faculty members.

\begin{tabular}{|c|c|c|c|c|}
\hline & $\begin{array}{c}\text { Total } \\
\mathbf{n}(\%)\end{array}$ & Demonstrator/ lecturer & Assistant professor & Associate/ full professor \\
\hline Searching for information & $212(82.17)$ & $32(96.97)$ & $77(84.62)$ & $103(76.87)^{*}$ \\
\hline Professional networking & $202(78.29)$ & $24(72.73)$ & $68(74.73)$ & $110(82.09)$ \\
\hline Learning & $196(75.97)$ & $27(81.82)$ & $72(79.12)$ & $97(72.39)$ \\
\hline Entertainment & $174(67.44)$ & $30(90.91)$ & $66(72.53)$ & $78(58.21)^{*}$ \\
\hline Community discussion & $158(61.24)$ & $21(63.64)$ & $52(57.14)$ & $85(63.43)$ \\
\hline Sharing resources & $137(53.1)$ & $12(36.36)$ & $57(62.64)$ & $68(50.75)^{*}$ \\
\hline Exchange ideas & $137(53.1)$ & $18(54.55)$ & $55(60.44)$ & $64(47.76)$ \\
\hline Making friends & $96(37.21)$ & $13(39.39)$ & $35(38.46)$ & $48(35.82)$ \\
\hline Other & $5(1.94)$ & $1(3.03)$ & $2(2.2)$ & $2(1.49)$ \\
\hline
\end{tabular}

\subsection{Purpose of Using Social Media}

Table 4 indicates the academic rank distribution with regard to the purposes for using social media. Searching for information $(82.17 \%)$ followed by professional networking (78.29\%) and dental learning (75.97\%) were the most popular purposes for using social media across faculty members. The chi-square and fisher's exact tests showed that demonstrators/lecturers were more likely to use social media to search for information and entertainment purposes when compared to the others $(p<0.001)$. However, assistant professors, associate and full professors were significantly more likely to use social media for sharing resources compared to demonstrators and lecturers $(\mathrm{p}<0.001)$.

\subsection{Perception of Social Media in Learning}

The responding faculty members agreed or strongly agreed that social media facilitates communications with students (77.91\%) and speeds up the process of providing results for students $(78.68 \%)$, followed by being useful in updating students with new resources $(79.46 \%)$, increasing the range of skill they can develop (77.91\%), and helps to share ideas with other educators $(84.11 \%)$ (Fig. 1). Most of the participants agreed or strongly agreed that the biggest concern with social media use is that it creates more demand for internet access $(33.72 \%)$, followed by an increase in their addictive potential (31.79\%) and lack of technical support $(28.3 \%)$; it raises concerns on direct contact with students $(25.58 \%)$, and requires more work and preparation (30.23\%) (Fig. 2).

\section{DISCUSSION}

Our study investigated the perception of using social media among dental faculty staff in three universities in Saudi Arabia as a learning tool. The results showed that the most common social media accounts used in the studied sample were WhatsApp, YouTube, Facebook, and Twitter, respectively. These findings are similar to the sample investigated by Aboalshamat et al. (2019), where WhatsApp was the most popular form of social media preferred by Saudi dentists [8]. In comparison to dentists from other countries, South African dentists used Google+ and Facebook more than any other platforms and the purpose was mainly personal rather than professional use [10]. Dentists in the United States reported that Facebook was the most popularly used social media account $[9,15]$. About $97 \%$ of the surveyed dentists used Facebook compared to LinkedIn (38\%) and Twitter (32\%) [15]. The reasons provided for using social media were highly related to marketing (91\%) or patient communication $(73 \%)$ [15]. It is not clear why there is such a difference between our results and prior studies. It might be due to cultural differences between Saudi Arabia, South Africa and the United States. Moreover, WhatsApp is a prevalent form of communication between families and friends in Saudi Arabia, which might be why dentists feel more familiar and confident to use on a professional level. It is advised to encourage dental instructors to use YouTube more to improve the traditional learning experience and motivate reflective thinking among students. Learning through watching videos can promote new dental/clinical techniques and improve dental skills, which is widely accepted by both students and demonstrators [16].

Our participants reported using multiple social media accounts for five to ten hours per week. The main purpose of using social media accounts among our sample was to seek information followed by professional networking and learning. This pattern of usage was also reported among physicians who reported surfing different social media platforms from two to three hours daily [17]. Out of the 300 surveyed medical consultants and residents, $76 \%$ thought that social media contributes to improving their knowledge and skills and should be used as an educational tool for different medical professions in Saudi Arabia [17]. It is not unusual for a dentist to use social media accounts professionally for learning new clinical procedures and for marketing purposes or self-advertisement by sharing clinical cases [8]. However, this is not always the case; Arnett et al. (2013) reported that many dental educators use social media mainly for personal rather than professional purposes [15]. It is common for people in Saudi Arabia to use social media daily for communication and entertainment, but not in education. However, this situation has dramatically changed since the Coronavirus pandemic (COVID 19). More Saudi academic staff has now incorporated the use of different social media accounts in their teaching to be able to reach out to dental students using online home-based learning. Nowadays, more and more educational videos are available on various social media platforms. 


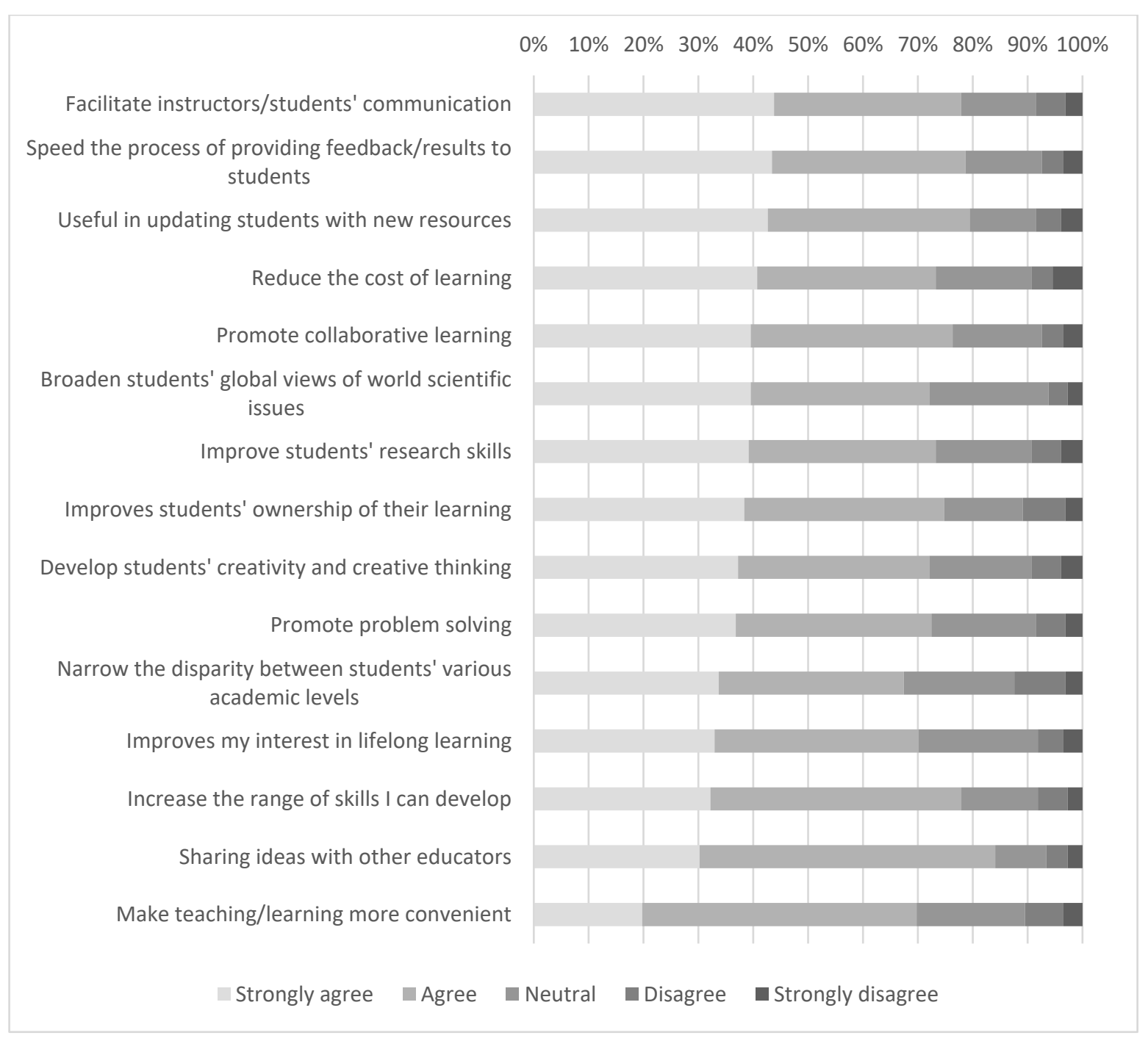

Fig. (1). Opinion of benefits that encourage dental faculty members to use social media in the learning environment.

More than $70 \%$ of the dental staff in our study believed that social media simplifies communication with students, helps provide results for students faster, and has made sharing ideas with other educators easier. While their most significant concern with social media use was that it is an internetdependent technology and may cause addictive potential. Furthermore, our participants raised concerns about direct contact with students through such channels and the potential lack of technical support. Similar concerns were reported in a study conducted in the UK, where $91 \%$ of the academic dental staff owned a computer and only $68 \%$ had access to the internet at home [18]. They also reported being less confident in their technical skills and using internet-based lectures as an educational tool [18].

Although student-tutor communication has become faster and more comfortable with all the available social media platforms, such communication may lead to unwanted behaviour and the absence of professionalism. Therefore, dental health professionals from all educational backgrounds need to be aware of the risks associated with social media usage as a tool with students $[8,15,19]$. Drawing professional boundaries and having privacy concerns were major factors preventing some dental educators from using social media with their students [15]. Social media should be used for educational and communicational purposes with students due to its multiple advantages. However, it should be structured first by using proper professional guidelines. For example, by providing an ethics training course on using social media professionally and legally to both staff and students. In addition, ensuring that a specific time for student-instructor communication through officially approved channels can eliminate the privacy breach concern. 
Create more demand on internet access facilities for students in the classroom

Increase my addictive potential to media and internet

Lack of proper classroom technical support for instructors

Raise concerns over direct contact with students

Require more work and preparation

Cause infringement on my privacy

Be time consuming more than they worth

Make it difficult to manage teaching and learning activities to students through social media

Be distractive to students

Require formal training

Raise concerns about students' academic integrity and motivation

Inhibits students' participation and affects their learning due to bullying and domination

Bullying and domination may inhibit my participation

Make the teaching/learning process boring

Cause infringement on students' privacy

Affects students' time management skills

Create additional cognitive load

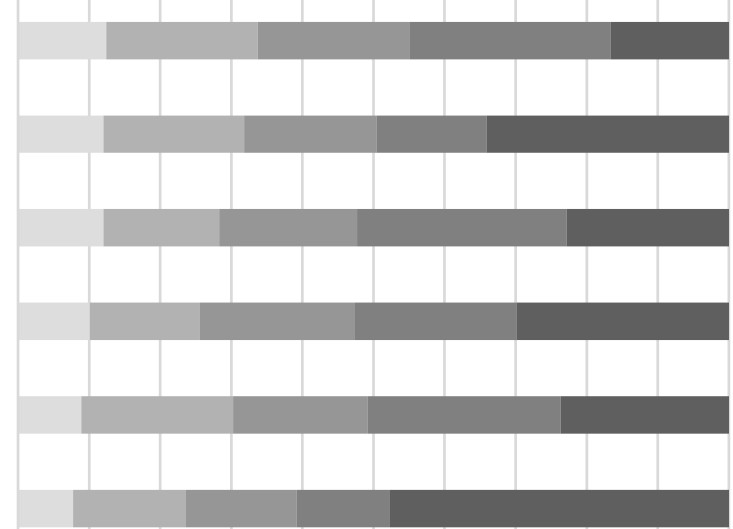

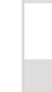

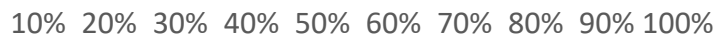

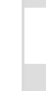
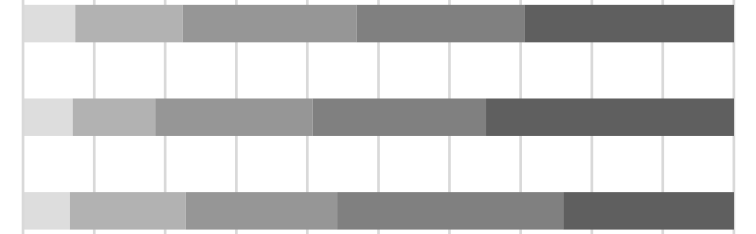

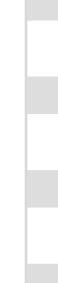

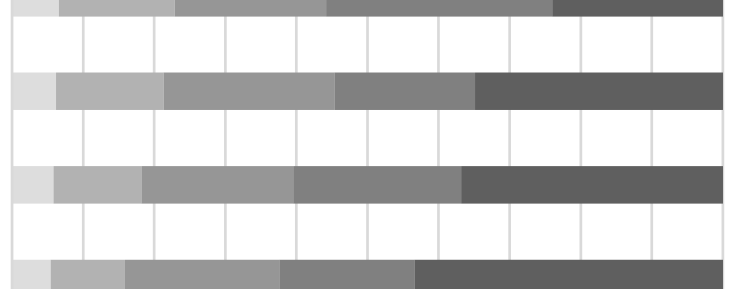

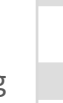

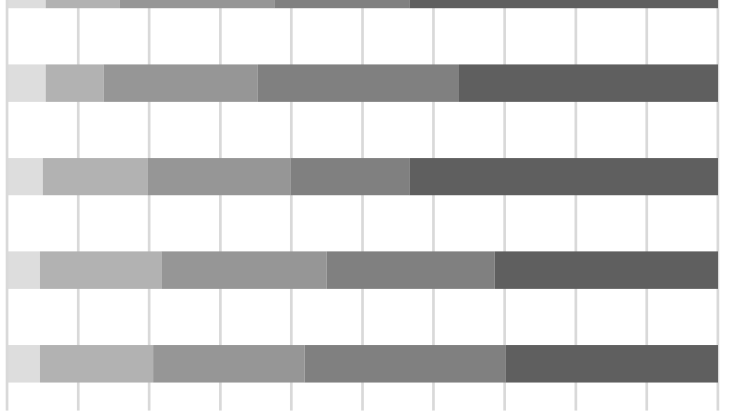

Strongly agree $\quad$ Agree $\quad$ Neutral $\quad$ Disagree $\quad$ Strongly disagree

Fig. (2). Opinion regarding the problems that prevent dental faculty members from using social media in the learning environment.

Due to the COVID-19 pandemic, education worldwide is sweeping towards e-learning. The presence of different social media platforms can support distance learning and help to engage and advance students' learning experiences in a secure and confidential environment. The Ministry of Education in Saudi Arabia is directed toward virtual lessons and broadcasting educational videos through social media like Facebook and YouTube. To further encourage the imple-mentation of social media in dental education, in 2016, supporting vision 2030, the pendulum of education shifted towards digital education supporting modern education.

Our study can provide insight into planning a future educational program that supports the modern direction of education. Our results were driven by dental staff, having various experiences and educational backgrounds, from three major universities in the Western Province in Saudi Arabia. However, the study has limitations that must be considered. One limitation is the use of a convenience sample from faculty members working only in public universities in the western province, limiting the generalizability of the results. Another limitation is the use of self-reported data, which can cause response bias. Future studies are recommended to explore further in-depth dental faculties' perspectives of using social media and explore other challenges that might be faced in 
adopting social media in dental education.

\section{CONCLUSION}

YouTube could be the main platform to deliver educational materials to dental students in Saudi Arabia. Dental faculty educators agreed that using social media will facilitate communication and education if it is properly integrated into dental curricula.

\section{ABBREVIATION}

COVID-19 $=$ Coronavirus disease 2019

\section{ETHICS APPROVAL AND CONSENT TO PARTI- CIPATE}

This study received approval from the Institutional Review Board of Umm Al-Qura University, Saudi Arabia, with ethical approval number 155-2019.

\section{HUMAN AND ANIMAL RIGHTS}

No animals were used in this research. All human research procedures followed were in accordance with the ethical standards of the committee responsible for human experimentation (institutional and national), and with the Helsinki Declaration of 1975, as revised in 2013.

\section{CONSENT FOR PUBLICATION}

All participants signed the consent before participating in the study.

\section{AVAILABILITY OF DATA AND MATERIALS}

The data that support the findings of this study are available from the corresponding author [M. R] upon reasonable request.

\section{FUNDING}

None.

\section{CONFLICT OF INTEREST}

The authors declare no conflict of interest, financial or otherwise.

\section{ACKNOWLEDGEMENTS}

The authors would like to acknowledge dental faculty members from King Abdul-Aziz University, Umm Al-Qura University and Taibah University.

\section{REFERENCES}

[1] Evan C. Twitter for teaching: Can social media be used to enhance the process of learning? Br J Educ Technol 2014; 45(5): 902-15. [http://dx.doi.org/10.1111/bjet.12099]

[2] McAndrew FT, Jeong HS. What does what on Facebook? Age, sex, and relationship status as predictors of Facebook use. Hum Comput Interact 2012; 28(6): 2359-65.

[3] George DR, Dellasega C. Use of social media in graduate-level medical humanities education: two pilot studies from Penn State College of Medicine. Med Teach 2011; 33(8): e429-34. [http://dx.doi.org/10.3109/0142159X.2011.586749]

[PMID: 21774639]

[4] Chickering A, Gamson ZF. Seven principles for good practice in undergraduate education. Am Assoc Higher Educ Bull 1987; pp. 3-7.

[5] Hake R. Interactive-engagement vs traditional methods: A sixthousand-student survey of mechanics test data for introductory physics courses. Am J Phys 1998; 66(1): 64-74.

[http://dx.doi.org/10.1119/1.18809]

[6] Prince M. Does active learning work? A review of the research. J Eng Educ 2004; 93(3): 223-31.

[http://dx.doi.org/10.1002/j.2168-9830.2004.tb00809.x]

[7] Michael J. Where's the evidence that active learning works? Adv Physiol Educ 2006; 30(4): 159-67.

[http://dx.doi.org/10.1152/advan.00053.2006] [PMID: 17108243]

[8] Aboalshamat K, Alkiyadi S, Alsaleh S, et al. Attitudes toward social media among practicing dentists and dental students in clinical years in Saudi Arabia. Open Dent J 2019; 13: 143-9.

[http://dx.doi.org/10.2174/1874210601913010143]

[9] Henry RK, Molnar A, Henry JC. A survey of US dental practices' use of social media. J Contemp Dent Pract 2012; 13(2): 137-41.

[http://dx.doi.org/10.5005/jp-journals-10024-1109] [PMID: 22665737]

[10] Snyman L, Visser JH. The adoption of social media and social media marketing by dentists in South Africa. SADJ 2014; 69(6): 258-, 260-264. [PMID: 26548200]

[11] Hamasha AA, Alghofaili N, Obaid A, et al. Social media utilization among dental practitioner in Riyadh, Saudi Arabia. Open Dent J 2019; 13: 101-6.

[http://dx.doi.org/10.2174/1874210601913010101]

[12] Gardner K. An online community of inquiry for reflective practice in an operative dentistry course. J Dent Educ 2012; 76(5): 641-50. [http://dx.doi.org/10.1002/j.0022-0337.2012.76.5.tb05298.x] [PMID: 22550110]

[13] Alshiekhly U, Arrar R, Barngkgei I, Dashash M. Facebook as a learning environment for teaching medical emergencies in dental practice. Educ Health (Abingdon) 2015; 28(3): 176-80. [http://dx.doi.org/10.4103/1357-6283.178609] [PMID: 26996641]

[14] Alsharqi L, Hashim K, Ahmed H. University students' perceptions of social media as a learning tool. Journal of Social Media in Society 2016; 5(1): 65-88.

[15] Arnett MR, Christensen HL, Nelson BA. A school-wide assessment of social media usage by students in a US dental school. Br Dent J 2014; 217(9): 531-5.

[http://dx.doi.org/10.1038/sj.bdj.2014.956] [PMID: 25377826]

[16] Knösel M, Jung K, Bleckmann A. YouTube, dentistry, and dental education. J Dent Educ 2011; 75(12): 1558-68.

[http://dx.doi.org/10.1002/j.0022-0337.2011.75.12.tb05215.x] [PMID: 22184594]

[17] Alanzi T, Al-Yami S. Physicians' attitude towards the use of social media for professional purposes in Saudi Arabia. Int J Telemed Appl 2019; 1-6.

[http://dx.doi.org/10.1155/2019/6323962]

[18] Walmsley AD, White DA, Eynon R, Somerfield L. The use of the Internet within a dental school. Eur J Dent Educ 2003; 7(1): 27-33. [http://dx.doi.org/10.1034/j.1600-0579.2003.00268.x] [PMID: 12542686]

[19] Chertien K, Goldman E, Beckman L, Kind T. It's your own risk: Medical students' perspective on online professionalism. Acad Med 2010; 10: 568-71 